\title{
O PROFESSOR DE CIÊNCIAS É COMO UM ANALISTA?
}

\author{
Alberto Viliani - inst. Física, Univ. São Paulo
}

Apoio parcial do CNPq

\section{Resumo}

Apresentamos, inicialmente, alguns resultados obtidos ao explorarmos a analogia entre a estrutura dinâmica da mudança de um sujeito num processo psicanalítico e num processo de aprendizagem das ciências. Em seguida, procuraremos explorar ainda mais a possível analogia entre psicanálise e educação em ciência, focalizando alguns pontos interessantes no processo de formação de um analista os quais podem dar sugestões para a formação de um professor. Concluiremos com considerações mais gerais que discutem alguns pontos acenados inicialmente.

\section{Abstract}

The analogy between the dynamic structure of a person's transformation within a psychoanalytic process and a person's transformation within a science learning process is discussed in this paper. The possible analogy between psycho-analysis and science education is explored further by focusing on some interesting aspects of the analysfs training process which can give insight into and suggestions about teacher education. 


\section{INTRODUÇÃO}

O século $X X$, sem dúvida, foi marcado por um fenómeno social importantíssimo: 0 desenvolvimento articulado da ciência e da tecnologia, que está tomando conta da vida humana de maneira progressiva, não sem algumas ambiguidades. De um lado, a medicina tem conseguido aliviar o nosso sofrimento, até prolongar a vida humana, mas também tornase cúmplice da violência organizada; de outro, a tecnologia tem facilitado a organização social e proporcionado bem-estar para inúmeras populações, mas também contribuído para o extermínio em massa. A ideologia normalmente associada à educação científica parece explorar os aspectos considerados benéficos do progresso científico e do correspondente controle social, silenciando a ambiguidade intrínseca a cada conquista científica: nessa visão, parece fundamental que todos apoiem a atividade científica e que recursos quase sem limites the sejam fornecidos. O sucesso dessa campanha no grande público parece basear-se na esperança de que a ciência e a tecnologia consigam afastar-nos de nossos limites e, quem sabe, da morte. Em nossa opinião, essa propaganda subliminar é enganosa e a educação científica não pode compactuar com ela. Trabalhos recentes na área têm chamado atenção para as limitações dessa maneira ufanista de considerar a ciência e apontado para a necessidade de complementar a educação em ciências mediante um processo sério de avaliação do status epistemológico e sociológico do saber científico (Norris, 1997), de maneira a torná-lo uma das opções possíveis para o aluno (Pacca \& Viliani, 1997). Também tem sido apontado o fracasso ao qual está fadado o ensino, quando se desconhecem as dificuldades e os conflitos que aparecem nos alunos que têm diferentes visões de mundo (Cobern, 1996; Cobern \& Aikenhead, 1997). Enfim, a prática atual do ensino de ciências está propondo uma reflexão aprofundada, de um lado focalizando sua fundamentação epistemológica e antropológica e, de outro, tomando a sério a necessidade de o estudante assumir uma responsabilidade pessoal frente ao saber científico. Wood et ai. (1991), por exemplo, propõem uma experiência na qual o professor abandona o papel de fonte do conhecimento científico para se tornar promotor da construção coletiva junto com a classe. A comunidade que aprende se responsabiliza por aquilo que considera válido na solução de seus problemas, tendo presente também as indicações da comunidade científica mais ampla. Análoga parece ser a sugestão dos que trabalham com uma didática fundada na ideia de problemas abertos (Duschl \& Gitomer, 1991; Gil-Perez, 1993). Na procura de soluções, o aluno entra em contato com as propostas, recentes e passadas, da comunidade científica e deve optar pelo grau de adesão que considera oportuno no caso com que lida. $O$ professor deixa de ser o único filtro nesse processo, pois, como suporte, visa a promover o encontro individual e/ou coletivo entre aluno e conhecimento científico.

Entre as várias disciplinas científico-humanistas, a psicanálise tem-se destacado como um baluarte na defesa das infinitas escolhas possíveis dos homens e na focalização das suas responsabilidades em assumir seus desejos e suas limitações, sem ceder à ilusão de uma vida sem dificuldades, problemas e sofrimentos. Essa batalha, em favor da subjetividade das escolhas e contra qualquer processo de massificação, tem chamado nossa atenção pela possibilidade de oferecer subsídios na perspectiva de se contrapor ao simplismo implícito em certas visões de educação científica. Em particular, a proposta lacaniana (veja, por exemplo, Dor, 1992 e 1995) que visa, de maneira explícita, confrontar o sujeito com sua falta radical (a separação inicial de algo que o completa), parece-nos poder ajudar o sujeito, de um lado, a suportar seu sofrimento inevitável devido ao confronto com 
seus limites e sua impotência e, de outro, a movimentar a sua busca sem fim de sua verdade subjetiva. Confronto do sujeito com seus limites no campo do conhecimento e busca sem fim do saber que se engancha com sua própria verdade subjetiva parecem-nos a finalidade principal do ensino de ciência: por isso, nosso interesse, específico pela psicanálise de orientação lacaniana. A psicanálise, constituindo-se essencialmente num processo de mudança do analisando na relação com ele mesmo, sugere-nos a possibilidade de. explorar uma analogia entre a estrutura dinâmica da mudança de um sujeito num processo psicanalítico e num processo de aprendizagem das ciências (Cabral \& Viliani, 1996;

Viliani \& Cabral, 1997). Os próprios Seminários de Lacan (por exemplo, Lacan, 1986 e 1995) oferecem muitas indicações a esse respeito (Viliani, 1997).

Neste trabalho, iniciaremos retomando rapidamente alguns dos resultados por nós obtidos nesse campo e já publicados; em seguida, procuraremos explorar ainda mais a possível analogia entre psicanálise e educação em ciência, focalizando alguns pontos interessantes no processo de formação de um analista os quais podem dar sugestões para a formação de um professor. Concluiremos com considerações mais gerais que discutem alguns pontos acenados inicialmente.

\section{APRENDIZAGEM EM CIÊNCIAS E PSICANÁLISE}

Do ponto de vista da dinâmica do processo que devem conduzir, tanto o analista quanto o professor se deparam com inúmeros problemas que podem ser resumidos em duas grandes tarefas: colaborar ativamente para que se realize a entrada no processo de análise ou de aprendizagem e sustentar o processo para que o sujeito atinja aquilo que puder alcançar. Na literatura sobre ensino de ciências, está sendo sempre mais focalizada a necessidade de investigar situações de ensino nas quais os sujeitos estão realmente envolvidos, em primeira pessoa, em uma procura de conhecimentos científicos; entretanto, tanto no Brasil quanto no Exterior, o mais comum é encontrar salas de aula onde os estudantes cumprem tarefas para obter boas notas, aprovação, diploma, sucesso, reconhecimento, no lugar de conhecimentos.

Por essa razão, aquilo que denominamos a entrada no processo de aprendizagem (o aluno decidir assumir a responsabilidade de sua aprendizagem) torna-se um evento a ser investigado preferencialmente. $\mathrm{O}$ que a psicanálise de orientação lacaniana pode sugerir a respeito?

Para responder a essa pergunta, utilizaremos, em parte, os elementos essenciais apresentados em um trabalho recente (Viliani \& Cabral, 1997a), no qual tentamos explorar a metáfora: analisando é como estudante e analista é como professor.

\section{AS ENTREVISTAS PRELIMINARES DE BASE PSICANALÍTICA}

Nas primeiras conversas entre 0 analista e 0 analisando, denominada ${ }^{\wedge}$ entrevistas preliminares, o primeiro procura estabelecer um contrato de trabalho com o segundo a respeito do número de sessões, do horário, da eventualidade de faltas, do pagamento, do 
período de férias e faz a promessa de que nada do que será dito sairá do consultório. Tudo isso constitui um compromisso entre as partes e funciona como contexto capaz de sustentar externamente o trabalho analítico. Trata-se de um contrato de trabalho, que poderá ser complementado e alterado, mediante mútuo acordo, ao longo do processo.

As entrevistas preliminares de orientação lacaniana (Quinet, 1995), que precedem o início da análise propriamente dita e que podem durar semanas ou até meses, têm três funções: transformar a queixa do paciente em sintoma analítico, instaurar a transferência e fazer um diagnóstico sobre a estrutura do paciente para poder estabelecer uma estratégia de direção da análise, tendo como base a transferência. A seguir, procuraremos explicitar cada uma dessas funções.

\section{TRANSFORMAÇÃO DA QUEIXA EM SINTOMA}

A transformação da queixa em sintoma destina-se a localizar a existência de alguma insatisfação, algum mal-estar genérico ou alguma queixa específica, para transformá-la na percepção de uma divisão interior ao paciente. Se a posição inicial do paciente for de recusa e de ceticismo, mesmo quanto a possibilidade de cura, posição típica de um início de análise a partir de uma imposição familiar ou social, o papel do analista é causar uma perturbação na posição fundamental do paciente, provocar uma abertura para uma interação. No caso mais favorável de o paciente trazer a queixa, cuja responsabilidade é atribuída a outro ou outros, o trabalho do analista consiste em levar o indivíduo a perceber sua posição subjetiva com relação à mesma.

\section{A INSTAURAÇÃO DA TRANSFERÊNCIA}

A instauração da transferência corresponde à instituição da posição do analista como sujeito suposto saber, ou seja, o analisando traz consigo a confiança de que o saber do psicanalista irá resolver seus problemas e o analista, por sua vez, confia que será capaz de sustentar o trabalho do paciente.

Algumas vezes, por alguma razão, o paciente se queixa, mas não reconhece no analista, que está à sua frente, a capacidade de resolver seus problemas; pode acontecer também que o analista, apesar de ouvir a queixa do paciente, não se implique com o mesmo. Tanto num caso como no outro, a transferência não se instaura. Para produzir efeitos sobre si mesmo, o analisando precisa expor-se e o analista, levá-lo a fazer questão sobre sua participação na queixa que o movimenta: qual seu papel nisso tudo?

\section{ELABORAÇÃO DE UM DIAGNÓSTICO PROVISÓRIO}

A elaboração de um diagnóstico provisório consiste em descobrir a estrutura clínica do sujeito, para poder orientá-lo no processo analítico. Fazer um diagnóstico da estrutura do analisando significa pôr em questão sua relação com a "castração" ${ }^{1}$. A aceitação ou a recusa da castração condiciona a evolução do desejo do sujeito e todo o movimento de procura de satisfações, as quais devem ser reconhecidas e aceitas como parciais e finitas. 
Conforme Quinet (1995), o diagnóstico sobre as estruturas é realizado a partir da fala do sujeito, pela maneira como articula suas relações fundamentais. Dessa perspectiva, as maneiras de o indivíduo lidar com a castração, através do trabalho de negação -recalque, desmentido e foraclusão (exclusão) - ou de aceitação parcial - sublimação - caracterizam estruturas. No caso do recalque, o sujeito sabe inconscientemente de sua impotência fundamental, mas não a aceita como constitutiva de seu ser; no caso do desmentido, o sujeito reconhece sua divisão, mas acredita que sua falha pode ser preenchida pelo fetiche; na foraclusão, ao contrário, o sujeito não sabe de sua impotência fundamental, por isso está atrelado a sonhos de onipotência, os quais não podem ser redimensionados mediante um processo normal de análise. Finalmente, na sublimação, há uma certa assunção da castração, ou seja, da lei que intima o sujeito a procurar e ultrapassar os bens particulares (Juranville, 1987).

\section{O AJUSTE DIDÁTICO INICIAL}

Explorando a analogia entre mudança na psicanálise e na aprendizagem, podemos sugerir que os encontros iniciais entre professores e alunos deveriam visar explicitamente a: estabelecer um contrato de trabalho capaz de compatibilizar as perspectivas de professores e alunos, evitando-se os abusos de poder e as fugas de responsabilidades; modificar a posição inicial do aluno, transformando sua insatisfação em problema a ser resolvido com uma busca; instaurar uma relação pedagógica transferencial, caracterizada^por um lado, pela confiança do estudante de que o professor irá efetivamente ajudá-lo a compreender o novo saber e, por outro, pela escolha do professor de se solidarizar com o processo de seu estudante e fazer um diagnóstico sobre as concepções do estudante, e sobretudo, sobre sua capacidade e disposição de trabalhar, perseguindo princípios científicos ou outras ideias fundamentais.

\section{O CONTRATO PEDAGÓGICO}

$\mathrm{Na}$ relação ensino-aprendizagem, o contrato consiste na definição do número de aulas, do horário, do conteúdo, do livro-texto, da metodologia de trabalho em classe, das tarefas de casa, da disponibilidade para atividades paralelas, das regras dos exames, do sistema de avaliação e promoção. A discussão desses fatores deveria tender a definir e a isolar o papel institucional do professor, criando uma expectativa de trabalho entre ele e os alunos, na qual haja espaço para que o primeiro desenvolva um papel de provocador da aprendizagem dos segundos. Estes compromissos iniciais, além de poderem ser modificados de comum acordo durante o caminho, podem também ser complementados por compromissos mais detalhados sobre o modo de trabalhar de estudantes e professor como, por exemplo, pensar em voz alta ou privilegiar as perguntas no lugar das respostas ou trabalhar em grupos ou manter um diário. A importância do contrato pedagógico pode ser percebida sobretudo nas situações nas quais a falta de sua explicitação conduz a impasses na relação entre professor e alunos, cada qual visando a compromissos diferentes (Viliani et ai., 1997). 


\section{A PROBLEMATIZAÇÃO}

A problematização consiste em estabelecer uma perspectiva comum na qual se vise a algo significativo para alunos e professor e, conseqüentemente, ao engajamento dos afores na procura do mesmo. Em particular, as tarefas a serem executadas pêlos alunos devem-se tornar desafios perturbadores capazes de mante-los envolvidos. Na ação docente, cada vez mais, o professor se depara com alunos apáticos e pouco interessados em aprender, Nesse caso, a tarefa do professor é surpreender o aluno, fazendo com que ele passe a acreditar que, mesmo na escola, existe algo de imprevisível e interessante. Esse efeito é obtido quando o conteúdo a ser aprendido se apresenta ou como ligado a algum tipo de interesse cultural específico do aluno, ou como potencialmente útil para obter alguma meta (institucional, pessoal, etc), ou como importante reforço da auto-imagem (para quem se vê como futuro cientista, tudo o que se refere à ciência deve ser privilegiado...) (Pintrich et ai., 1993). Também não devemos esquecer que um conteúdo pode ser considerado interessante simplesmente porque o professor ou um colega muito estimado assim o consideram (Viliani \& Cabral, 1997); entretanto, esse tipo de interesse está mais ligado ao fenómeno da relação pedagógica transferencial que analisaremos em seguida.

Há duas estratégias diferentes de problematizar um conteúdo: tornar explícita a presença de lacunas, num campo de conhecimento no qual o aluno quer ser minimamente competente, ou provocar conflitos, em situações que o aluno quer resolver. Torna-se, então, tarefa do professor levar o aluno a ter um posicionamento ativo diante da "falha" percebida, ou seja, transformar a correspondente insatisfação em problema que o aluno quer resolver. A dificuldade dessa tarefa consiste em favorecer a emergência de ressonâncias mais profundas no aluno, de maneira que as soluções encontradas (sempre parciais) nunca acabem com o querer entender melhor.

\section{A RELAÇÃO PEDAGÓGICA TRANSFERENCIAL}

A relação pedagógica transferencial consiste na instauração de uma confiança recíproca entre professor e aluno, de modo que, de início, o aluno acredite no saber científico e didático do professor, dispondo-se a segui-lo, e o professor acredite na flexibilidade e potencialidade do aluno, dispondo-se a orientá-lo, propondo-lhe atividades e intervindo em suas falas. Na literatura, pouca atenção tem sido dada a esse aspecto que parece condicionar, pelo menos no início, tanto o envolvimento do aluno na experiência de aprendizagem quanto a paralisação do processo. O aluno, às vezes, parece inicialmente interessado no problema, mas não acredita que o professor possa ajudá-lo a satisfazer esse interesse, porque o considera pouco competente ou muito comprometido com exigências burocráticas. Outras vezes, o aluno acredita demais no professor e executa as tarefas escolares para atender seu pedido e "desejo", tentando reproduzir o discurso do mestre sem realizar uma produção pessoal. Às vezes, o professor confia pouco no aluno e responde a essa demanda, reforçando a posição do outro; outras vezes, cai na tentação narcisista de se colocar como modelo de produção de conhecimento e considera satisfatório o fato de o aluno repetir essa imagem: em ambas as situações, vai impedir a elaboração de um trabalho pelo aluno, situação muito comum no ensino tradicional. Em nossa visão, é o interesse do 
professor pêlos processos de mudança que sustenta o trabalho do aluno e permite que este supere as dificuldades ou decepções experimentadas ao aprofundar cada problema novo. Nesse trabalho, aos poucos, o aluno se reconhece implicado nos esquemas que utiliza, nas ações que realiza e nas palavras que pronuncia. Inclusive pode ser levado a se perguntar 0 porque dele utilizar sempre o mesmo esquema ou dele se defender sistematicamente frente a questionamentos, até surgirem implicações genuínas com as tarefas.

\section{O DIAGNÓSTICO PEDAGÓGICO}

A realização de um diagnóstico consiste em levantar as justificativas que sustentam as concepções alternativas dos alunos e, mais em geral, seus traços característicos e que influenciam a tendência ou a resistência às mudanças. Em particular, parece significativo, desde o início das aulas, delinear, mesmo que de forma provisória, a relação do aluno com as leis, as definições gerais, os princípios científicos ou com alguma ideia básica, a partir de suas falas. Quatro tipos de relações parecem importantes. O primeiro tipo, o mais comum, é o seguinte: para o aluno, o princípio sintetiza várias situações já analisadas, mas, frente a novos problemas, seu caráter de conhecimento que pode ser aplicado a prio-ri, parece ser "sufocado". O seguinte é dado pela admissão, por parte do estudante, de que o conhecimento científico não é autónomo, pois está submetido à concordância com um outro saber, único e absolutamente vinculante, ligado a alguma autoridade relevante, familiar, religiosa ou de outra natureza. O terceiro tipo de relação é fornecido pelo abandono da procura de ideias gerais vinculantes; o aluno memoriza e não se prende a qualquer necessidade de coerência: o princípio enquanto tal é "excluído". O quarto tipo refere-se ao aluno que está, desde logo, à procura do essencial, das regras vinculantes e, encontrando-as, utiliza-as sistematicamente, pelo menos até surgirem objeções fundadas: o princípio é "admitido".

É importante salientar que, no caso do ensino, a relação do aluno com os princípios científicos deve ser considerada como uma relação provisória e não como uma estrutura permanente: o diagnóstico tem a função-de orientar na procura de atividades didáti-cas adequadas que a modifiquem tanto quanto possível. Tais atividades serão diferenciadas, dependendo de cada tipo de relação enfrentada, de maneira a gerar efetivos conflitos cognitivos ou, pelo menos, substitutos adequados.

Exemplos referentes à primeira e à quarta relação são comuns em nossas classes. Referem-se ao aluno que aceita os princípios somente a posteriori e, frente a novas situações, fica em dúvida, acabando por voltar às concepções espontâneas. Outros referemse ao aluno que aceita trabalhar com os princípios científicos e que, apesar das diferenças com a visão de senso comum, enfrenta com segurança as dificuldades e os conflitos cognitivos.

O exemplo que segue ilustra a segunda relação. Gunstone (1992) relata-nos o fato de um aluno que se recusava a abandonar um modelo espontâneo de eletricidade, sustentada nos ensinamentos do pai, eletricista, em nada adiantando os argumentos do professor ou dos colegas. Era a verdade do pai em confronto com a verdade do professor. Podemos interpretar o conflito desse indivíduo como oscilando entre dois saberes: um atribuído ao pai, confiável e absoluto, e outro atribuído ao professor, provisório e descartável, apesar das evidências empíricas e/ou lógicas. Esse último saber não podia 
conter leis ou princípios físicos vinculantes: houve um "desmentido" deles.

A terceira relação pode ser ilustrada pela fala de um aluno que, frente às observações do professor e dos colegas sobre um cálculo por ele realizado de maneira inadequada, o qual confundia soma com multiplicação, acabou satisfazendo às exigências dos outros, mas comentou que a modificação era irrelevante (Cabral, 1998). Esse aluno considerava qualquer esquema como possível e transitava de um a outro, passando por cima da contradição que ele mesmo havia percebido. Podemos interpretar sua fala como indicativa de uma "exclusão" dos princípios.

\section{UMA 'APLICAÇÃO' SIMPLES}

Para concluir daremos um exemplo de ' aplicação' do modelo cotriído a partir da articulação entre contrato pedagógico, proble-matização, transferência pedagógica e diagnóstico, interpretando, de maneira global, os eventos de um curso de segundo grau sobre as Leis de Newton descritos em Ferreira (1997). Nesse curso, houve um planejamento de atividades variadas e com objetivos que, no entender da professora, estavam claros: fazer com que os alunos se apropriassem do esquema newtoniano. Houve empenho da mesma na elaboração e na execução do planejamento assim como na discussão dos pontos que para ela eram tomados como essenciais sobre as Leis de Newton. Seu objetivo era propor atividades que provocassem o debate entre os estudantes. Como resultado, a maioria dos alunos não atingiu a compreensão das articulações impostas pelas Leis de Newton, como era inicialmente esperado. Apenas alguns apresentaram o que pode ser descrito como evolução de suas representações, indicando que o processo de ensino, de alguma forma, marcou-os. Houve, também, um aumento no número de alunos que participaram de entrevistas optativas fora do horário de aula e, em alguns casos, foram revelados efetivos esforços para elaborar informações alcançadas progressivamente. Entretanto, os estudantes não se comportavam como se estivessem participando de uma experiência para eles significativa, pois quase sempre se limitavam a cumprir as tarefas propostas, tentando responder do jeito que achavam que iria agradar à professora. Houve progressos, mas não tanto quanto era esperado por esta.

Podemos dizer que a diferença entre as expectativas e os resultados alcançados pêlos alunos pode ser interpretada a partir de uma posição inadequada da professora no processo. Tal inadequação pode ser assim caracterizada:

- o contrato inicial permaneceu implícito e, como consequência, a ambiguidade daí originada deu margem às recriminações dos estudantes e às vacilações da professora;

- a problematização foi parcial, pois atingiu apenas uma parcela reduzida dos interesses e das necessidades dos alunos. Apesar destes se envolverem em várias das atividades propostas, eles não chegaram a modificar sua posição pessoal frente ao saber a ser alcançado, utilizando-o como saber próprio;

- a condução do processo, a partir da instauração da transferência, foi inadequada, pois, apesar de o processo ter tido um início favorável (os estudantes confiaram na professora como guia competente), esta não conseguiu instaurar uma reflexão com eles sobre suas queixas, nem transformar suas resistências frente ao novo método em desejo de participar de uma experiência nova; 
- finalmente, o diagnóstico pedagógico, apesar de ter sido realizado durante o curso, não atingiu o planejamento das atividades, ou seja, ele localizoLftrês grupos - os estudantes que aceitavam trabalhar com os princípios científicos, apesar de serem diferentes do senso comum; os alunos que pareciam aceitar os princípios, porém, nas novas situações, preferiam voltar às concepções espontâneas e os estudantes decididamente refratários aos princípios -, mas a professora não usou as informações do mesmo para estabelecer atividades diferenciadas.

\section{A FORMAÇÃO DO ANALISTA E DO PROFESSOR}

O caráter promissor dos resultados obtidos, ao se explorarem as analogias entre 0 processo de aprendizagem em ciências e o processo de mudança numa análise, sugere-nos a possibilidade de avançar na análise dos contextos e das estratégias utilizados pêlos profissionais da psicanálise, para obter ulteriores sugestões na gestão do ensino de ciências. A perspectiva que considera a experiência radical de análise como suporte da formação do analista sugere que a formação da competência profissional do professor preste mais atenção a este aspecto. A competência do analista em fomentar a modificação de sua relação com o analisando ao longo do processo está baseada na sua longa experiência em localizar e trabalhar suas sucessivas identificações imaginárias, até reconhecer e admitir, de maneira radical que, apesar de nenhuma satisfação poder ser plena, a procura deve ser contínua. De maneira análoga, estamos sugerindo que a competência profissional do professor em modificar continuamente a relação com seus estudantes rumo à autonomia intelectual e subjetiva destes está baseada na sua longa experiência em localizar e trabalhar suas concepções espontâneas básicas e sua visão de mundo, até reconhecer e admitir que, apesar de nenhum conhecimento ser absoluto, a procura deve ser contínua.

A seguir, delinearemos, mais em detalhes, algumas etapas que, em nossa visão, caracterizam a formação do analista, tentando transferi-las, na medida do possível, para a formação do professor. Antes de nos perguntarmos até que ponto é possível levar à frente a exploração de analogias e quais as especificida-des de cada processo em jogo, perguntas legítimas e que devem ser enfrentadas a seu tempo, chamamos atenção para a questão: a operação de transferência conduz a um conjunto interessante de sugestões, ou pelo menos de reflexões, sobre a formação do professor? É tentando responder a essa pergunta que descreveremos tanto o processo de formação de um analista como o de um professor de ciências.

\section{A FORMAÇÃO DO ANALISTA}

A escolha da profissão de psicanalista, às vezes, se dá no começo da escolha profissional, movida pelo desejo de ajudar as pessoas a conhecerem as "profundezas" de sua psique; outras vezes, consiste numa mudança improvisada de rumos anteriormente escolhidos, motivada pelo encontro efetivo com a análise ou com um analista. Entretanto, qualquer desses caminhos caracteriza-se necessariamente por dois componentes: um ex-

periencial, que consiste em levar até seu término natural uma análise individual; outro 
teórico, que consiste em entrar em contato com os livros dos autores mais importantes ou participar de cursos nos quais se ensina a teoria psicanalítica. A transmissão desta não apresenta diferenças substanciais daquela de outras disciplinas: uso de um aparato conceituai específico e de uma linguagem própria, que, no entanto, tem uma superposição com a do senso comum, envolvendo, então, a possibilidade de promover entendimentos ambíguos e de alimentar concepções alternativas. Entretanto, o aspecto que mais nos interessa e que é mais fundamental na formação de um analista, diz respeito à sua própria experiência analítica: o desenvolvimento de uma capacidade de lidar, de alguma maneira, com a impossibilidade de obter uma satisfação completa e a construção de uma nova relação com o Outro (aproximadamente, o conjunto dos valores recebidos da sociedade familiar e civil e aceitos pelo sujeito).

Como se realiza essa ' formação' pæriencial?

Lacan, que era considerado um analista extraordinário, costumava desconversar quando alguém pedia para ser analisado porque queria "se conhecer melhor". Para ele essa intenção não constituía um bom começo, pois era interpretada como um não querer enfrentar seus problemas. Mesmo para alguém que queria ser analista, um bom começo era ter uma insatisfação pessoal, não conseguir lidar com ela, apresentar sintomas ininteligíveis. A procura de uma ajuda que colocava o analista na posição de Sujeito Suposto Saber, ou seja, de alguém que sabe trabalhar a insatisfação do analisando e no qual, então, este pode confiar. Isso cria uma relação de transferência denominada imaginária, pois o sujeito imagina que o outro resolverá seus problemas. Essa transferência é que sustenta o falar do sujeito sobre suas queixas até ele perceber que os problemas são seus e que ninguém, a não ser ele mesmo é responsável pela maneira como as dificuldades reais ou imaginárias são enfrentadas. Essa mudança de posição é denominada de retificação subjetiva, pois o sujeito se implica em seus sintomas e implica também o analista, que vira o parceiro-guia de uma caminhada. Essa deverá levar à derrubada dos vários sintomas que aparecerão daí para frente. A análise propriamente dita começa a partir dessa mudança. Sem ela não há análise, somente conversas preliminares, como já descrevemos anteriormente. Essa mudança implica a transformação da relação transferencial de imaginária para simbólica. $O$ sintoma começa a mostrar sua dupla face. De um lado, sinaliza um saber do analisando, um saber sobre seu desejo e, portanto, sua falta; de outro, sinaliza uma produção causal, uma tendência a se exprimir na maneira mais fácil, no contexto. Nesse sentido o sintoma é um saber que não quer ficar calado.

O sujeito, ao ter percebido que ele está na origem do seu sintoma, conclui que, se ele fizer aquilo que ele acha que o analista quer dele, os problemas serão resolvidos automaticamente.

Não é bem assim, mas, de fato, se o analisando falar livremente, se ele trabalhar sobre as indicações que emergem na análise, e se 0 analista for suficientemente competente para não atrapalhar esse trabalho, os efeitos começarão a aparecer de duas maneiras: desaparecimento dos sintomas que 0 incomodavam e progressivo desaparecimento dos vínculos que assujeitavam o sujeito ao Outro. O sujeito descobre que ele está além de sua identificação com seus pais, sua família, seu trabalho, seus amores, sua ideologia, seus... Ele começa a viver mais efetivamente a máxima analítica de que nada preenche a falta radical.

Alcançado esse patamar, o sujeito pode entrar numa outra fase chamada de retificação objetiva, na qual ele pode reconstituir radicalmente sua subjetividade, 
atravessando sua fantasia e identificando-se com seu sintoma fundamental, ou pode desistir da análise. Para quem pretende ser analista, é indispensável que se entregue à primeira escolha.

De fato, o analisando pode já estar satisfeito com o efeito terapêutico que efë obteve: uma libertação de amarras que o prendiam e o correspondente desaparecimento dos sintomas desagradáveis. Pode, também, sentir-se desarvorado demais e querer voltar às antigas identificações ou querer experimentar outros saberes mais tranquilizadores: uma religião ou uma crença esotérica ou alguma outra escolha, capazes de prometer a salvação. Mas o sujeito pode, também, querer ir até o fim do processo analítico, identificando-se com algo que resiste à simbolização e que, portanto, não vem do Outro. De um lado, ele percebe a falta que está atrás de todas as suas fantasias, as quais incessantemente o iludem na procura de preenchê-la. De outro lado, ele experimenta que não pode apoiar-se em algo que vem do Outro e, conseqüen-temente, não deve dar satisfações a esse Outro. Ele se autoriza por si mesmo. O conteúdo de suas escolhas não será fundamentalmente diferente daquele das outras pessoas, pois o sujeito sabe que é um ser humano como qualquer outro; a diferença parece ser na qualidade da adesão a essas escolhas: elas não são feitas para satisfazer a outros ou ao Outro. O sujeito constitui-se como indivíduo singular e diferente dos outros, organizando e administrando, em uma das maneiras possíveis, suas pulsões fundamentais. Por isso, responsabiliza-se totalmente por suas escolhas, sendo ele mesmo a justificativa. Nesse momento, ele está na posição de analista, independentemente de exercitar ou não essa função. Está pronto e capacitado para poder ajudar os outros a enfrentarem um processo semelhante, pois ele experimentou, de maneira efetiva, que ninguém pode ocupar permanentemente o lugar do Outro e está em condição de suportar e até conduzir o analisando a reconhecer que, de certo momento em diante, não precisará mais de sua ajuda como analista.

\section{A FORMAÇÃO DO PROFESSOR}

As considerações, desenvolvidas anteriormente, servir-nos-ão de guia para tentar caracterizar a formação do professor de uma forma nova. Isso não implica negar todas as inúmeras contribuições e reflexões, às vezes originais e quase sempre interessantes, que a literatura sobre ensino de ciência nos oferece. Pelo contrário, a maioria dessas contribuições será, de alguma forma, retomada. A novidade parece-nos residir no enfoque que organiza essas contribuições.

Também a escolha da profissão de professor, apesar de menos prestigiada pela sociedade, pode-se dar no início da escolha profissional, movida pelo desejo de transmitir às pessoas um conhecimento importante e ajudando-as a compreender a Ciência. Outras vezes, trata-se de uma mudança do rumo anteriormente escolhido, ou porque o sujeito experimentou ocasionalmente dar aulas e acabou gostando da nova posição, ou porque sobrou para ele, de fato, somente essa alternativa e ele sentiu necessidade de uma preparação mais adequada. Entretanto, qualquer que seja o caminho escolhido, a formação do professor de ciências consistirá de uma série de cursos teóricos e de estágios práticos, que deveriam capacitá-lo a exercer, adequadamente, a profissão.

Neste ponto, a analogia com a formação do psicanalista sugere-nos uma reinterpretação das características da formação do professor num sentido específico. De um 
lado, os cursos devem fazer com que o futuro professor domine, teoricamente, um determinado conteúdo científico e didático, os quais o capacitam a preparar e planejar suas intervenções didáticas e científicas na sala de aula e a realizá-las de maneiras adequadas. Num trabalho anterior (Viliani \& Pacca, 1996), descrevemos detalhadamente em que consiste essa competência disciplinar e didática, que constitui a meta da formação profissional: ela é o resultado do conjunto de disciplinas que o currículo apresenta como obrigatórias ou optativas para o futuro professor.

Entretanto, existe uma outra competência, a chamada dialógica, que consiste essencialmente em escutar o aluno e conduzi-lo até ele se posicionar pessoalmente frente ao conhecimento científico. Essa competência, descrita com bastante detalhe num trabalho recente (Pacca \& Viliani, 1997), exige, fundamentalmente, uma correspondente experiência vital. Sem ela, o professor, mesmo dominando muito o campo científico e didático, será inadequado na condução e na sustentação do processo que leva os alunos a pensarem por si mesmos aquilo que aprenderam. Trata-se de desenvolver a capacidade de lidar, de alguma maneira, com a impossibilidade de um conhecimento absoluto, assumindo, então, a responsabilidade e o risco daquilo no qual se confia. Em conclusão, também, na formação do professor, podemos vislumbrar dois componentes, um teórico e um ' experiência!' .

Como se realiza essa ' formaçãœxperiência!' ?

A formação experiência! começa quando o futuro professor depara com algum conhecimento científico ou didático que ele gostaria de ter e do qual, portanto, sente falta. Ele supõe que seu professor tenha esse conhecimento e espera recebê-lo do mesmo, possivelmente com pouco esforço. Instaura-se, então, uma relação pedagógica transferencial que podemos denominar de imaginária, porque o aprendiz imagina que 0 professor vai resolver seu problema.

Se o professor for suficientemente hábil colocará, cedo ou tarde, o futuro professor na situação de perceber que o efeito da transmissão do conhecimento é inadequado. Aquilo que o futuro professor consegue produzir somente em parte (às vezes bem pequena) assemelha-se àquilo que é a norma científica ou didática. Essa produção, à semelhança do sintoma analítico, mostra sua dupla face. De um lado, sinaliza que o futuro professor continua tendo uma falta que não gostaria de ter e, de outro, aponta a existência de um modo de produzir pelo caminho mais fácil (obstáculo epistemológico). O aprendiz se sente insatisfeito até perceber que a solução do problema está em suas mãos, no sentido de que o conhecimento a ser adquirido exige o envolvimento do sujeito, além da ajuda específica do professor. Essa mudança fundamental de posição frente ao conhecimento científico marca a entrada no processo de aprendizagem efetivo. Sem trabalho do futuro professor, não há aprendizagem significativa para a futura profissão, somente ilusão de aprendizagem. A relação pedagógica transferencial tornou-se simbólica, pois conseguiu incluir professor e futuro professor na solução do problema deste último: transformar sua fala em outra compatível com o conhecimento estabelecido. Nesta fase, o aluno progressivamente abandona, pelo menos no contexto escolar, seus ' erros' e enfrenta seus obstáculos epis temológicos até atingir um conhecimento bastante adequado. A partir desse ponto, se o professor permitir e incentivar o caminho desse aluno que pretende tornar-se professor, abrem-se novas perspectivas: começar a pensar por si mesmo ou desistir do processo. Claramente, a formação do futuro professor exige a primeira escolha.

$\mathrm{O}$ aluno pode ficar satisfeito com aquilo que alcançou, pois, afinal, o resultado das avaliações enfrentadas é bem positivo e suas palavras, pelo menos no contexto da sala de 
aula, são compatíveis com as do livro didático. Pode até fazer uso desse conhecimento para mostrá-lo aos outros e ao professor em particular. Pode, também, deixar de lado esse conhecimento que ele sente como sendo muito árido e abstraio e diferente daquilo que o senso comum usa e com o qual é possível comunicar-se com todos os outros.

No entanto, é possível, também, um outro caminho: continuar na busca da produção de conhecimento próprio, para resolver problemas reais importantes. Nessa experiência, o futuro professor perceberá que as coisas não estão tão resolvidas: cada entendimento alcançado está acompanhado de várias dúvidas e é preciso deixar de lado coisas que até podem ser importantes; enfim, a segurança plena está além das possibilidades humanas. Por isso, para resolver, ao menos parcialmente, seu problema, o futuro professor terá que conviver com as suas crenças ou hipóteses fundamentais, das quais não quer abrir mão, e assumir a responsabilidade e o risco que delas derivam.

Na elaboração de uma dissertação ou tese, na execução de um projeto experimental, na programação e execução de uma aula real, na tentativa de convencer seus eventuais alunos, o futuro professor experimentará, novamente, a sensação de que ninguém pode resolver a priori seu problema, porque, de fato, o problema pode ser resolvido somente em parte: ele deverá enfrentá-lo na prática, administrando sua intuição e suas tendências básicas e depois procurando analisá-lo de maneira mais completa.

Nesse momento, o sujeito não se apoia em mais ninguém, a não ser nele mesmo e nas suas peculiaridades. Ele virou "professor". Seu antigo professor pode dar conselhos, mas quem decide o que fazer com um conhecimento parcialmente satisfatório deve ser o próprio sujeito, pois as consequências de suas opções devem ser por ele assumidas. $\mathrm{O}$ elemento essencial dessa experiência é aceitar a insatisfação que, junto com a vontade de saber, mantém o sujeito amarrado ao problema: ela difere tanto da frustração de não ter conseguido esclarecer o problema (atitude que leva a abandonar a procura), quanto da ilusão de ter encontrado tudo aquilo que era significativo (atitude que também leva a abandonar a procura por razões opostas). Sem essa experiência, o futuro professor não será capaz de induzir e sustentar o processo dos seus alunos rumo a reconhecer e enfrentar sua insatisfação e a assumir uma responsabilidade frente ao conhecimento adquirido e, finalmente, produzido.

Concluindo, podemos definir como meta prioritária, a ser necessariamente alcançada no processo de educação das pessoas que vivem numa sociedade globalizada, torná-las capazes de compreender e, conseqüentemente, influenciar as decisões mais importantes que dizem respeito à melhoria da qualidade de vida, pessoal e comunitária, inclusive à própria sobrevivência. A educação em ciências, sem dúvida, tem uma fatia importante nessa tarefa e os professores de ciências têm o papel fundamental de apontar diretamente para a responsabilidade em relação ao saber científico e à formação da cidadania num país com grandes desigualdades sociais. Em nossa opinião conduzir os estudantes a se responsabilizarem frente ao conhecimento científico e ao seu uso somente pode ser tarefa de alguém que tenha realizado essa escolha pessoal.

\section{ALGUMAS PERSPECTIVAS PARA O FUTURO}

Nas páginas anteriores, procuramos mostrar como a exploração, bastante imediata, de uma analogia entre o processo de mudança durante a aprendizagem e durante uma 
psicanálise pode fornecer algumas sugestões, que nos parecem interessantes, quanto à compreensão e ao gerenciamento do processo de ensino, inclusive estendendo-se à formação do futuro professor.

As analogias têm um grande poder de organização e de orientação. A perspectiva de uma analogia sugere a possibilidade de transferências, guardando, é claro, os devidos limites entre o que acontece num campo e no outro. Em nosso caso, a fertilidade da analogia parece muito grande, porque culturalmente o analista é pensa- do como aquele que sabe ajudar as pessoas a mudarem, principalmente ouvindo-as. No ensino de ciências, o professor teria um papel semelhante: ajudar os alunos a mudarem seus conhecimentos, ouvindo-os. É possível ir mais além, ou seja, a analogia entre os processos pode ser ulteriormente explorada e em que medida a psicanálise pode auxiliar na tarefa de ensinar as ciências?

Quanto à possibilidade de uma maior exploração da analogia entre os processos, nossa convicção é positiva: nós mesmos já temos feito isso em outros trabalhos recentes, chamando atenção para paradoxos implícitos nas tarefas de psicanalisar e de educar (Viliani, 1998), ao focalizar o ' desejo de analista' , que consiste na procura incessante de fazer funcionar o dispositivo analítico, como correspondente de um hipotético ' desejo de professor' , que consistiria em lançar, continuamente, apelos, mesmo que imptítos, para que o aluno se responsabilize pelo conhecimento alcançado (Viliani \& Cabral, 1997a) e desenvolvendo ulteriores paralelismos nas fases marcantes dos dois processos (Viliani, 1998a). Além disso, parece-nos que um campo fértil, ainda não completamente explorado, é o dos instrumentos utilizados pelo analista para alcançar seus objetivos.

Contudo, a possibilidade de semelhanças entre educar em ciências e psicanalisar não implica a ausência de diferenças significativas. Tentando iniciar uma discussão se, afinal, o professor é realmente como um analista, podemos levantar as seguintes considerações.

1) O conteúdo envolvido num processo de ensino de ciências e de análise evidentemente é diferente, mais do que isso, o objetivo do professor é fazer com que o aluno entre em contato com um conteúdo específico por ele (professor) escolhido, ao passo que o objetivo do analista é fazer com que o analisando entre em contato com sua fala e com aquilo que ele (analisando) considera importante. Para executar essa tarefa com competência, o professor deve ter um conhecimento aprofundado sobre o assunto a ser ensinado, ao passo que o analista não deve ter um conhecimento aprofundado sobre o tema escolhido pelo analisando. De um lado (ensino), domina um conteúdo consciente, sendo tarefa do professor marcar as semelhanças e as diferenças entre os significados do aluno e os da ciência em jogo; de outro lado (análise), o mais importante é o conteúdo inconsciente, sendo tarefa do analista marcar as ressonâncias entre os significantes do analisando.

Nesse sentido, o professor não é como um analista.

2) Se olharmos para as relações entre o aluno, o saber científico e o professor, devemos reconhecer que a dinâmica que regula essas interáções depende, de maneira fundamental, de elementos inconscientes. Tais elementos, pelo menos no início do processo de ensinar, são totalmente desconhecidos do professor, assim como o são, no início do processo de análise, os elementos que regulam a relação entre analisando, analista e o saber envolvido no processo. Isso permite que uma 
série de instrumentos utilizados pelo professor, como o privilégio às perguntas, a fala que surpreende ou que acalma, o diagnóstico, a interpretação, o contrato pedagógico, o corte das aulas tenham uma forte analogia com os correspondentes instrumentos utilizados pelo analista. Nesse sentido, o professor é como um analista.

3) O professor de ciências tem um compromisso institucional com uma determinada cultura e visão de mundo. Esse compromisso o leva a conduzir suas aulas de maneira que os alunos consigam perceber, pelo menos, a importância que a ciência tem no contexto de nossa sociedade como instrumento de promoção da sobrevivência coletiva e de progresso comum e também como instrumento de destruição e de domínio. Além disso, as aulas são conduzidas num contexto coletivo, que deve obedecer a determinadas regras para poder funcionar a contento. Pelo contrário a relação analisando-analista (na perspectiva lacaniana) é estritamente individual e o analista não tem nenhum compromisso com determinadas culturas e visões de mundo, sendo sua meta fazer com que o desejo efetivo do analisando seja por este reconhecido. Isso impede que o analista possa se tornar um modelo de comportamento para o analisando e que as escolhas do analista possam ser propostas como solução para os problemas do analisando. Entretanto, no caso do ensino de ciências, o professor pode tornar-se, de forma provisória, um modelo de comportamento para seus alunos e sugerir ou até cobrar deles determinadas atitudes cívicas exigidas pelo contexto coletivo. Nesse sentido, o professor não é como um analista.

4) Finalmente, a experiência de análise é considerada uma experiência singular e marcante, que leva os sujeitos a se posicionarem frente a seus problemas e a operarem escolhas. Todo o trabalho do analista aponta nessa direção. Os trabalhos mais recentes na área de ensino de ciências sugerem que alunos e professores são guiados, positiva ou negativamente, pelas experiências de ensino e aprendizagem que os marcaram, daí a necessidade de pensar o trabalho do professor como orientado pela perspectiva de conduzir os alunos a fazerem uma experiência marcante de aprendizagem, que os leve a se posicionarem frente ao conhecimento científico e a escolher o que fazer com ele. Assim como na análise o resultado essencial deveria ser a aceitação por parte do sujeito de "não desistir de seu desejo", apesar de o mesmo não poder ser satisfeito, o resultado fundamental da experiência de aprendizagem deveria consistir na aceitação de que o conhecimento deve ser procurado, apesar de ser sempre parcial.

Isso supõe, do lado do' professor, tanto o abandono final de quaduer postura de mestre quanto a aceitação de qualquer escolha realizada pelo aluno em conformidade com sua verdade subjetiva. Escolha que pode implicar o privilégio de outras culturas e outros conhecimentos alternativos. Nessa altura, o professor poderá auxiliar no que diz respeito à avaliação, por parte do aprendiz, sobre o grau de confiabilidade dos vários conhecimentos em jogo. Manter uma relação com o aluno, na qual exista lugar e clima para qualquer escolha deste, parece-nos condição necessária para a emergência de uma escolha pessoal. Nesse sentido, o professor é como um analista que, por princípio, deve aceitar qualquer escolha do analisando, mesmo que contraste com seus valores pessoais. Claramente, tanto 
para o professor quanto para o analista é muito difícil manter operante esse ' desejo' de ser superado, entretanto ele deveria ser recuperado cada vez que esmorecesse ou ficasse de lado.

Retomando nossas considerações iniciais, podemos dizer que o aumento progressivo do consumo das drogas, das permitidas e das proibidas, e o da utilização da tecnologia, principalmente do computador na administração da vida dos homens, aponta para duas características, aparentemente interligadas: escapar do sofrimento e do confronto com um vazio interior insuportável e tornar-se mais produtivo e eficiente. Todos nós, quem mais, quem menos, utilizamos tanto as drogas quanto a tecnologia mais sofisticada. Tudo poderia fazer pensar que estamos indo para o melhor dos mundos, no qual ansiedades e sofrimentos poderão ser debelados rapidamente, deixando-nos num estado de satisfação; simultaneamente a automação resolverá os problemas de nossas vidas, nos deixando tempo para curtir nossa felicidade. Talvez se consiga até acoplar a tecnologia ao fornecimento das drogas necessárias para nossa satisfação sem limite... Dificilmente alguém, a não ser um fanático da ordem e do controle humano, poderá negar que uma solução desse tipo tem algo de profundamente errado.

Nossa hipótese é que homens e mulheres, para viverem como tais, devem enfrentar tanto o confronto com seu vazio quanto o esforço de "pensar", mesmo que isso carregue sofrimento. Sofrimento gerado pela necessidade de escolhas e dos correspondentes riscos de errar; e, também, pelo insuportável peso de responder por aquilo que foi escolhido e por aquilo que foi perdido. De fato, sempre em nossa hipótese, enfrentar o vazio significa aceitar que não existeifiada que possa nos satisfazer de uma vez e, conseqüen-temente, devemos procurar, incessantemente, novos bens ou renovar os antigos. Ter que renovar, continuamente, nossa busca significa aceitar que não existe nada que constitua um conhecimento satisfatório e definitivo. Nessa perspectiva, ajudar os homens a "pensarem" ou a enfrentarem o vazio interior não devem ser tarefas tão diferentes.

Com base nessas considerações, fica evidente que a exploração ulterior da analogia entre as tarefas de ensinar e de analisar exige um controle dos limites, ou seja, a seleção cuidadosa daquilo que tem sentido transferir de um campo para o outro. Esse controle, em princípio, dá-se tanto pelo conhecimento aprofundado do campo ao qual a analogia vai ser estendida quanto a partir do conhecimento aprofundado do campo que fornece as analogias. Infelizmente, nossa situação não é tão privilegiada: conhecemos de maneira profissional o campo do ensino de ciências e de maneira amadora, via leituras, participação em cursos e experiência de análise, o campo da psicanálise, na orientação lacaniana. Esperamos que nosso trabalho tenha a felicidade de parecer frutífero, convidando outros pesquisadores tanto para apontar e debater eventuais lacunas ou imprecisões quanto para realizar aprofundamentos futuros.

\section{REFERÊNCIAS}

CABRAL, T.C.B. (1998) Contribuições da Psicanálise à Educação Matemática; a Lógica da intervenção nos processos de Aprendizagem. São Paulo: Fac. Educação, Universidade de São Paulo. (Doutorado). 
CABRAL, T.C.B. \& VILLANI, A. (1996) Analogias para o Ensino de Ciências e Matemática; Contribuições da Psicanálise. In:

Reunião da Associação Nacional de Pesquisadores em Educação (ANPED), 19, Caxambu.

COBERN, W.W. (1996) Woridview Theory and Conceptual Change in Science Education. Science Education, 80(5), 579-610.

COBERN, W.W.\& AIKENHEAD, G.S. (1997) Cultural Aspect of Learning Science. In: Fraser, B. \& TOBIN, K. (Eds.) International Handbook on Science Education, Kluwer Academic Publishers.

DOR, J. (1992) Introdução 'a leitura de Lacan. I; O inconsciente estruturado como uma linguagem. Porto Alegre, Artes Médicas.

DOR, J. (1995) Introdução 'a leitura de Lacan. II; Estrutura do sujeito. Porto Alegre, Artes Médicas.

DUSCHL, R.A. \& GITOMER, D.H. (1991) Epistemological Perspective on Conceptual Change; Implications for Educational Practi-ce. Journal of Research in Science Teaching, 28(9) 839-858

FERREIRA, M. P. P. (1997) Análise e Interpretação de um curso de segundo grau sobre as Leis de Newton. São Paulo, Fac. Educação, Universidade de São Paulo. (Mestrado).

GIL-PEREZ, D. (1993) Contribución de la História y de la Filosofia de las ciências ai desarrollo de un modelo de ensenanza/aprendizaje como investigación. Ensenãnza de las Ciências, 1 1(2), 197-212.

GUNSTONE, R.F. (1992) Constructivism and metacognition; Theoretical issue and classroom studies. In: DUIT, R.; Goldberg, F.; Niedderer, H. (Eds.) fíesearch in Physics Learning;

Theoretical Issues and Empirical Studies. IPN. Kiel, 129-140.

HALLIDAY, M. (1978) Language as Social Semiotic. Londres: Arnold.

LACAN, J. (1986) O Seminário. Livro 1; os escritos técnicos de Freud. Rio de Janeiro: Ed. J.Zahar.

LACAN, J. (1995) O Seminário. Livro 2; o eu na teoria de Freud e na técnica da psicanálise. 4 ed. Rio de Janeiro: Ed. J.Zahar.

JURANVILLE, A. (1987) Lacan e a Filosofia. Rio de Janeiro: Ed. Jorge Zahar.

NORRIS, S.T. (1997) Intellectual Independence for Nonscientist and Other content- 
Transcendent Goals of Science Education. Science Education, 81(2), 239-258.

PACCA, J.L.A. \& VILLANI, A. (1997) A Competência dialógica do professor de ciências no Brasil, i n: Atas da Associação Nacional de Pesquisadores em Educação (ANPED), 20, Disquete do GT de Didática, Caxambu (M.G.).

PINTRICH, P.R.; MARX, R.W.\& BOYLE, R.A., (1993) Beyond Cold Conceptual Change; The Role of Motivational Beliefs and Classroom Contextuai Factors in Ihe Process of Conceptual Change. Review of Educational Research, 63(2), 167-199.

QUINET, A.: (1995) As 4+1 Condições da Análise. $3^{\mathrm{a}}$ ed. Rio de Janeiro; Jorge Zahar.

SHANK, R.; ABELSON, P. (1977) Scripts, pians, goals and understanding. Hilisdale, MJ: Lawrence Eribaum Associates.

VILLANI, A, (1997) Explorando Seminários de Lacan... para uma educação em ciências. In: Seminário apresentado num curso de Pós-graduação da Fac. de Educação da Universidade de São Paulo. (Não publicado).

VILLANI, A. (1998) Psicanálise e educação; Tarefas "Intrigantes"? Trabalho submetido a Estilos da Clínica.

VILLANI, A. (1998a) Contribuições da Psicanálise para a formação do professor de ciências. In: Escola de Verão - Prática de Ensino de Biologia, Física e Química, 4, Uberlândia, MG. Atas da... em publicação.

VILLANI, A.' ' \& CABRAL, T.C. B. (1997) Mudança conceituai, Subjetividade e Psicanálise. Investigações em Ensino de Ciências, 2(1) pp. 43-61.

VILLANI, A. \& CABRAL, T.C.B. (1997a) Analogies for Teaching and Learning Science. Roma (Itália): Trabalho apresentado no Congresso da European Science Education Research Association, 1, Roma.

VILLANI, A. \& PACCA, J.L.A. (1996) Construtivismo, Conhecimento Científico e Habilidade Didática no Ensino de Ciências. Revista da Faculdade de Educação da USP, (em publicação).

VILLANI, A.; FERREIRA, M.P.P. \& FIORAVANTE, M.A.C. (1997) Contribuições para o ensino de Ciências; O Ajuste Inicial. In: Encontro Nacional de Pesquisadores em Ensino de Ciências, 1, Águas de Lindóia, SP.

WOOD, T.; COBB, P.;YACKEL, E. (1991) Change in Teaching Mathematics; A Case Study. American Educational Research Journal, 28(3), pp 587-616. 


\section{Correspondência:}

Prof. Alberto Viliani, Depto. Física Aplicada, Instituto de Física, Universidade de São Paulo. Caixa Postal 66318 - São Paulo, SP - cep 05315-970. Correio eletrônico: avillani@if.usp.br. Submetido em 06/11/97, aceito para publicação em 26/02/1999. 